\title{
EFFECTIVENESS OF ETCHING WITH PHOSPHORIC ACID WHEN ASSOCIATED WITH RUBBING TECHNIQUE
}

\author{
Naji Kharouf', Francois Reitzer', Tarek Ashi ${ }^{2}$, Noor Daras ${ }^{3}$, Youssef Haikel', Davide Mancino ${ }^{1}$ \\ 'Department of Conservative Dentistry and Endodontics, Faculty of Dental Medicine, INSERM 1121, University of Strasbourg, France \\ ${ }^{2}$ Private Practice, Germany \\ ${ }^{3}$ Department of Odontology, Loma Linda University, Loma Linda, CA, USA
}

\begin{abstract}
INTRODUCTION: Some dental adhesive systems require an etching step using phosphoric acid in order to prepare dentin and enamel surfaces. This treatment modifies the surface characteristics and the chemical compositions of these hard tissues.

ОвJестіves: The aim of this in vitro study was to analyze chemical and microscopic effects of acid etching with rubbing technique on dental tissues.

MATERIAL AND METHODs: Sixteen extracted teeth were obtained. Two etching techniques (with and without rubbing) were used to treat the enamel and dentin surfaces. Scanning electron microscopy (SEM) and energy-dispersive $\mathrm{X}$-ray spectroscopy (EDX) were used to evaluate morphological and chemical changes of the enamel and dentin surfaces. Collected data were statistically analyzed by $\chi^{2}$ and Mann-Whitney rank sum tests.

RESULTS: The enamel that was etched with rubbing technique for $30 \mathrm{~s}$ showed a great dissolution at inter-prismatic enamel level. The dentin, which was etched with rubbing technique for $15 \mathrm{~s}$, revealed a larger tubules diameter and more open tubules than without rubbing technique. There were more silica particles on dentin etched by rubbing than without rubbing technique. Chemical analyses (EDX) showed that a dental surface etched using $37 \%$ phosphoric acid with rubbing technique revealed a surface rich in calcium, with a $\mathrm{Ca} / \mathrm{P}$ ratio $=1.66 \pm 0.05$ near to $\mathrm{Ca} / \mathrm{P}$ ratio $=1.67$ of hydroxyapatite.

ConcLusions: Although phosphoric acid cleans the dental surface, it causes salts precipitation on the etched dental surface; these salts can be removed more efficiently by rubbing the acid and rinsing it, providing an optimal interface for the bonding.
\end{abstract}

KEY wORDS: demineralization, etching, phosphoric acid, rubbing technique.

J Stoma 2021; 74, 1: 16-21

DOI: https://doi.org/10.5114/jos.2021.104693

\section{INTRODUCTION}

Dental enamel is an epithelial tissue that covers the coronal part of tooth. It is the most mineralized and rigid tissue in the human body, and the most important structure for esthetics and functionality of teeth $[1,2]$. On the other hand, dentin is a mesenchymal tissue, very rich in collagen fibers, and less mineralized than enamel [3]. In a dental restoration or repair, both tissues cannot be prepared in the same way. Bonding of biomaterials to the enamel has become a routine, whereas bonding to the dentin has been considered a more complicated treatment due to its complex composition and histology [4].

\section{JOURNAL OF} STOMATOLOGY CZASOPISMO STOMATOLOGICZNE

AdDRESS FOR CORRESPONDENCE: Naji Kharouf, Department of Conservative Dentistry and Endodontics, Faculty of Dental Medicine, INSERM 1121, University of Strasbourg, France, e-mail: dentistenajikharouf@gmail.com

RECEIVED: 19.11.2020 • ACCEPTED: 07.12.2020 • PUBLISHED: 30.03.2021 
The precise preparation of a tooth includes shaping the cavity and preparing the substrate for restoration [5]. A smear layer usually covers the tooth surface where the bonding occurs after the preparation procedure. This layer is formed on dentin during the preparation with hand instruments or burs [6]. Various dental burs can be used, which can possibly change the formation and thickness of smear layer $[7,8]$. Several studies showed that a low dentin-resin ratio strength would be observed with a large thickness of smear layer $[9,10]$. Clinical results of dental restoration on the dentin depend on a hybridization, which is produced between adhesive resin and partially demineralized dentin. Previous studies have shown the importance of eliminating the smear layer in the process of forming a hybrid layer and obtaining the best adhesion $[11,12]$. Adhesion to dentin improves with complete removal of smear layer, and modifying the exposure of peritubular and inter-tubular dentin [13]. Dentin etching is usually performed with an acidic agent to remove the layer of smear [14]. In dentistry, phosphoric acid is the most used acid conditioner [15]. Different techniques applied in cavity preparation may causea modification of the smearlayer characteristics [16]. There are no studies regarding the application procedure of phosphoric acid, whether it has to be rubbed or just applied on the tooth surface.

\section{OBJECTIVES}

The purpose of this in vitro study was to analyze the effects of acid etching microscopically and chemically using rubbing technique on the dental tissues with scanning electron microscopy (SEM) and X-ray energy-dispersive spectroscopy (EDX). The null hypothesis was that there were no changes in the chemical composition and morphological structure of enamel or dentin after etching process between two different etching techniques.

\section{MATERIAL AND METHODS}

Sixteen freshly extracted teeth, human maxillary third molars, were obtained under a patient-informed consent (ethics committee of Strasbourg University Hospital, protocol No. 2018-89). These teeth were washed with a saline solution and then stored at $4^{\circ} \mathrm{C}$ in $70 \%$ ethanol $[17,18]$.

The teeth were divided into two groups. The first group consisted of eight teeth; the enamel of these teeth was prepared with dental diamond red bur (Komet, Lemgo, Germany). After that, this group was sub-divided into two sub-groups with four teeth each. The first subgroup was treated with $37 \%$ phosphoric acid (ITENA, Paris, France) for $30 \mathrm{~s}$. The second sub-group was etched and rubbed with $37 \%$ phosphoric acid using a microbrush for $30 \mathrm{~s}$.
The second group consisted of eight teeth; the dentin of these teeth was prepared with dental diamond red burs. After that, this group was sub-divided into two sub-groups containing four teeth each. The first subgroup was treated with $37 \%$ phosphoric acid for $15 \mathrm{~s}$. The second sub-group was etched and rubbed with $37 \%$ phosphoric acid using a micro-brush for $15 \mathrm{~s}$. After the etching procedure, all the samples were rinsed with distilled water for $15 \mathrm{~s}$.

The samples were then dehydrated in a graded ethanol solutions and sputter-coated with a gold-palladium alloys (20/80) using Hummer JR sputtering device (Technics, CA, USA). Subsequently, Quanta 250 FEG scanning electron microscope (FEI Company, Eindhoven, The Netherlands) was used for the observation of 5 zones for each coated specimens. The chemical analyses of these specimens were performed with energy dispersive X-ray microanalysis (EDX) (EDAX Octane Plus spectrometer, Mahwah, NJ 07430, USA) of five zones of $443 \mu \mathrm{m}^{2}$ randomly taken for each sample.

The collected data were analyzed with Sigma Plot (release 11.2, Systat Software, Inc., San Jose, CA, USA). Mann-Whitney rank sum test was applied for the comparisons, first, of the open tubule diameters with or without rubbing the phosphoric acid, and second, of the Ca mass percentages for the enamel and dentin after etching with or without rubbing. $\chi^{2}$ test was applied to compare the proportions of open dentinal tubules in etched dentin with or without rubbing. A significant level at $\alpha=0.05$ was adopted for all tests.

\section{RESULTS}

\section{SCANNING ELECTRON MICROSCOPY OBSERVATIONS OF THE ENAMEL SAMPLES}

The enamel that was etched with the rubbing technique for $30 \mathrm{~s}$ using a micro-brush (Figure 1A) showed a great dissolution of the inter-prismatic enamel when compared to the enamel etched without the rubbing technique (Figure 1B).

\section{SCANNING ELECTRON MICROSCOPY OBSERVATIONS OF DENTIN SURFACE}

The dentin that was etched with the rubbing technique for $15 \mathrm{~s}$ using a micro-brush (Figure 2A) demonstrated a greater dissolution of the peritubular dentin, larger tubule diameters, and more open tubules (Table 1) compared to the dentin etched without rubbing (Figure 2B).

A superficial layer of residual material was observed (Figure 2). It can be noted that this layer appeared more in the group that was treated with the rubbing technique than in the group that was treated without rubbing. 

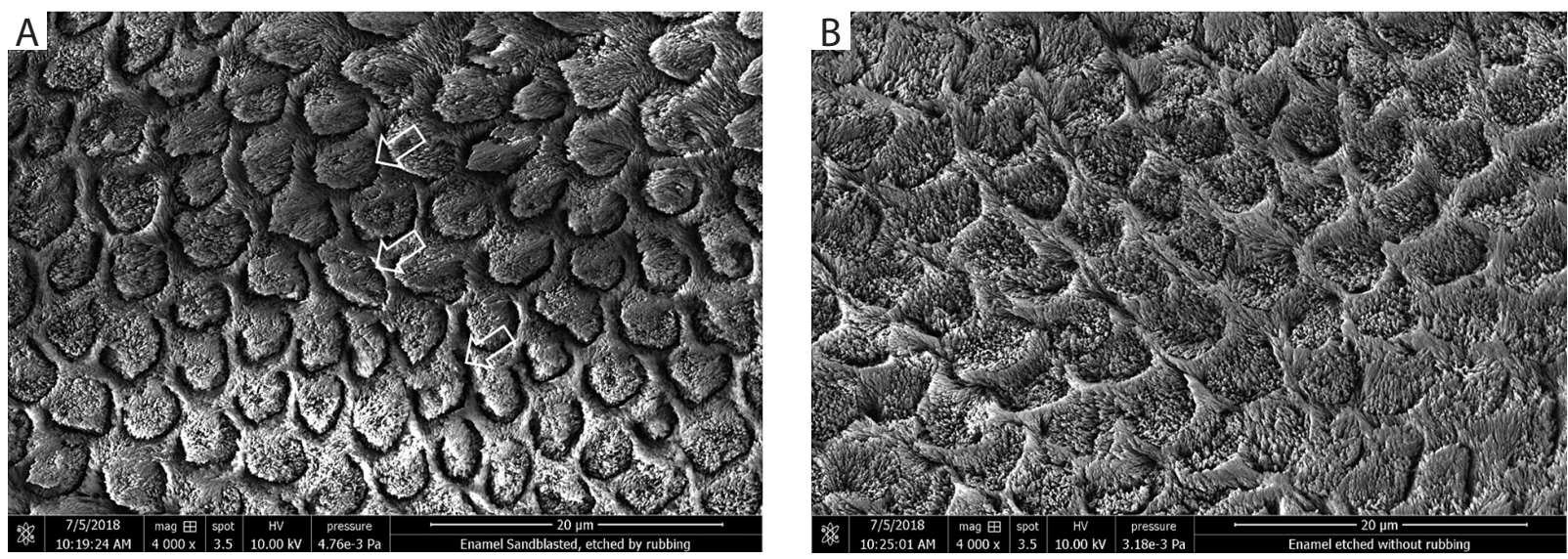

FIGURE 1. A) Higher magnification of the enamel surface ( $\times 4000$ magnification) showing a higher demineralized inter-rod enamel (arrows) after etching by 37\% phosphoric acid with the rubbing technique. B) Scanning electron microscopy micrograph ( $\times 4000$ magnification) illustrating the typical etched enamel exposed by $37 \%$ phosphoric acid
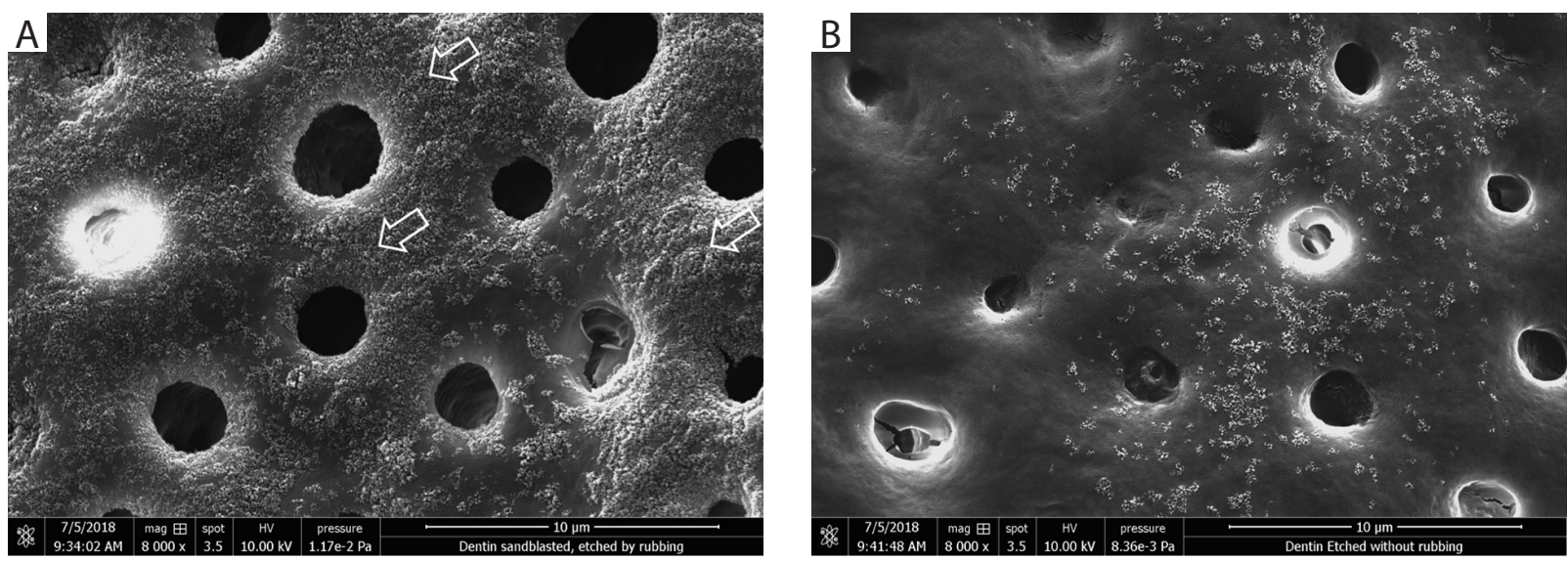

FIGURE 2. A) Higher magnification ( $\times 8000$ magnification) showing a larger tubules' diameter and the amount of silica particles (arrows) remaining on a dentin specimen etched by $37 \%$ phosphoric acid with the rubbing technique. B) Scanning electron microscopy micrograph (×8000 magnification) illustrating the typical etched dentin exposed by $37 \%$ phosphoric acid

TABLE 1. Mean values and standard deviations of open tubules' diameter and relative amount of open dentinal tubules in dentin surface for two different etching protocols (zones of $443 \mu^{2}$ )

\begin{tabular}{|l|c|c|}
\hline \multicolumn{2}{|c|}{ Dentin etched } & Dentin etched with rubbing \\
\hline Open tubules diameter $(\mu \mathrm{m})$ & $1.9 \pm 0.4(n=129)$ & $2.44 \pm 0.69(n=190)$ \\
\hline Relative number of open tubules $(\%)$ & $63^{*}$ & $89^{* *}$ \\
\hline
\end{tabular}

TABLE 2. Mass percentage of calcium (mean \pm standard deviation) in dentin and enamel surface for the two etching protocols measured on five zones of $443 \mu \mathrm{m}^{2}$ each

\begin{tabular}{|l|c|c|c|c|}
\hline & Enamel etched & Enamel etched with rubbing & Dentin etched & Dentin etched with rubbing \\
\hline Ca mass (\%) & $27.47 \pm 1.67$ & $30.19 \pm 1.32$ & $1.26 \pm 0.39$ & $4.84 \pm 1.66$ \\
\hline
\end{tabular}

\section{CHEMICAL ANALYSIS}

The analyses of superficial layer in the dentin samples of residual material by EDX indicated that the par- ticles attached to the surface that were visualized by SEM were silica particles, specifically, the silica used to thicken the acid gel. Silica nano-particles on the enamel surface were not observed. 
The chemical composition of the enamel treated with or without the rubbing technique exhibited calcium mass percentages (means and standard deviations), as described in Table 2.

The chemical composition of dentin treated with or without the rubbing technique demonstrated calcium mass percentages, as described in Table 2.

\section{STATISTICAL ANALYSES}

Concerning the relative amount of open dentinal tubules, there was a significant difference between the proportions observed in the dentin etched traditionally (without the rubbing technique) and the dentin etched with the rubbing technique ( $\chi^{2}$ test, $p<0.05$ ).

The differences between median values of the diameters of open tubules and the calcium mass percentages in the dentin, whether etched with the rubbing technique or etched traditionally, were greater than expected (Mann-Whitney test, $p<0.05$ ).

Concerning the calcium mass percentages, there was a significant difference between the medians corresponding to the enamel etched using the rubbing technique and the enamel etched traditionally (Mann-Whitney test, $p<0.05$ ).

The null hypothesis of insensitivity of the enamel or the dentin samples to different etching techniques was rejected $(p<a)$.

\section{DISCUSSION}

In this study, the scanning electron microscope (SEM) was used to observe the dental tissues surface after two preparation techniques (traditional etching and etching using the rubbing technique). Dentists need an optimal quality of dental restoration. Poor performance of bonding agents results from bonding the smear layer rather than to the tooth itself [19].

In the present study, the smear layer on the dentin surface, which was formed during the use of diamond was removed by etching with $37 \%$ phosphoric acid for $15 \mathrm{~s}$ (Figure 2), and the enamel surface was cleaned by etching with $37 \%$ phosphoric acid for $30 \mathrm{~s}$ (Figure 1). It appears that etching with phosphoric acid was able to fully clean the enamel and dentin surface. A micro-brush was used in the etching stage by rubbing the phosphoric acid on the dentin for 15 seconds, and on the enamel for 30 seconds.

SEM images showed that the rubbing action revealed a dentin surface with greater number and larger diameter of the exposed dentin tubules (Figure 2A) than that of not rubbed dentin surface (Figure $2 \mathrm{~B}$ ). The micromechanical interlocking of an adhesive in the demineralized dentin is the primary critical factor in determining sufficient bond [20]. The application of phosphoric acid for $15 \mathrm{~s}$ demineralized the dentin and exposed a colla- gen matrix [21]. We assume that the rubbing action reactivated the acid effect, pushed it in the tubules in order to open them more, and demineralized the peritubular dentin (larger diameter).

The silica particles attached to the dentin surface were more present in the rubbed samples. Silica is used to thicken the etching gel and it is not totally eliminated by only washing with water [22]. Although, the small silica particles $(10-20 \mathrm{~nm})$ were found, they were able to penetrate into the dental surface [23]. The use of acids to treat the dentin in collagen is becoming positively charged, which in turn, shows grater affinity to the negative silica particles. The rubbing technique demonstrates a greater infiltration capacity of the silica particles in the dentin surface. These silica nanoparticles may have an impact on the dentin bonding ability, as an outcome of impairing bonding material infiltration. No silica nanoparticles were found on the enamel that consisted of aligned rods. Each rod includes tightly packed apatite crystals with strong intermolecular forces and highenergy surfaces [24, 25].

In the present study, SEM images showed that the rubbing action revealed the enamel surface with inter-prismatic enamel more demineralized than prismatic enamel. This is due to the structure of prismatic enamel that is mineralized over $95 \%$, and contains aligned fiber-like apatite crystals with different orientations in the head and tail areas. Inter-prismatic enamel is enriched in organic matter $[25,26]$. Other study reported that the differences in the demineralization degree might be due to variations in crystallite orientation in the enamel rods [27]. Here, the demineralization of inter-prismatic enamel was improved by the rubbing technique; additionally, it enhanced the porosity (Figure 1A). The infiltration of adhesive resins into the porous surface is responsible for the mechanical bonding of adhesive systems to enamel [28]. According to our results, the rubbing effect increases the surface porosity, which is better for micro-mechanical bonding retention.

The degree of demineralization of dentin and enamel surface depends on the type and concentration of acid, in addition to the etching time [29]. There are no studies showing the effect of etching and using rubbing on the degree of demineralization.

EDX analysis (Table 2) showed that the mean percentages of calcium in the surface layer of dentin and enamel etched by the rubbing technique was higher than in the surfaces etched without rubbing. The depth in EDX analysis was around $1 \mu \mathrm{m}$ (depending on high voltage), and we assume that the rubbing action and rinsing for $15 \mathrm{~s}$ eliminated organic and salt debris on dental surfaces. Therefore, the EDX analyses, after these exclusions, showed an increase in calcium content of the clean surfaces.

Some studies observed that etching enamel or dentin with phosphoric acid with concentrations under $27 \%$ creates dicalcium phosphate dihydrate (DCPD). Higher 
concentration of phosphoric acid can lead to an early creation of monocalcium phosphate monohydrate (MCPM). While the DCPD precipitate could remain on the dental surface after rinsing, MCPM is simpler to dissolve by rinsing due to its different solubility in water [30].

We hypothesize that etching with $37 \%$ phosphoric acid and rubbing it with a micro-brush would not keep the $\mathrm{MCPM}(\mathrm{Ca} / \mathrm{P}$ ratio $=0.5)[31]$ completely attached to the etched surface, and with $15 \mathrm{~s}$ rinsing, the precipitate would be completely removed. EDX analysis of the dental surface that was etched using the rubbing technique showed a surface rich in calcium (Table 2), with $\mathrm{Ca} / \mathrm{P}$ ratio $=1.66 \pm 0.05$ near to $\mathrm{Ca} / \mathrm{P}$ ratio $=1.67$ of hydroxyapatite. Contrariwise, EDX analysis of the dental surface etched without rubbing showed a surface less rich in calcium (Table 2), with $\mathrm{Ca} / \mathrm{P}$ ratio $=1.59 \pm 0.04$.

The equation $1.59=1.67 \varkappa+0.5(1-\varkappa)$ revealed the percentage of MCPM and hydroxyapatite on the dental surface that was etched without the rubbing technique. They accounted for $36 \%$ and $64 \%$, respectively. In the above-mentioned equation, 1.59 is the value of $\mathrm{Ca} / \mathrm{P}$ ratio of the dental surface etched without the rubbing action, $x$ is the MCPM percentage on the dental surface etched without the rubbing action, 1.67 is the value of $\mathrm{Ca} / \mathrm{P}$ ratio of hydroxyapatite, and 0.5 is the value of $\mathrm{Ca} / \mathrm{P}$ ratio of $\mathrm{MCPM}$.

Therefore, rubbing action and rinsing for $15 \mathrm{~s}$ would leave a clean surface without MCPM, rich in hydroxyapatite crystallites, and more available for bonding. The hydroxyapatite on the etched surface of enamel and dentin contributes without a doubt to the adhesive performance, in addition to micro-mechanical hybridization.

Other study showed that the dissolved calcium and its precipitates were removed after 30 seconds water rinsing [32]. However, this study could not answer the question whether the effect of rubbing technique causes dental sensitivity, which should be studied clinically. This can be considered a limitation of this work. Obliquely oriented tubules hinders the visualization of the existence of debris within apparently opened tubules and in the measurement of dentinal tubule diameters in some SEM graphs.

According to the results of our present investigation, etching and rubbing with micro-brush showed important effects on the dentin surface (tubules were larger and the surface was richer in calcium). Etched and rubbed enamels demonstrated an increase in microporosity and a hydroxyapatite-rich surface that could be very important regarding the formation of ionic bonds of the adhesive's monomers with hydroxyapatite's $\mathrm{Ca}$.

\section{CONCLUSIONS}

Within the limitations of this study, phosphoric acid definitely removes the smear layer and cleans the dental surface. Nevertheless, etching with phosphoric acid causes salts precipitation on the etched dental surfaces. These salts can be removed more efficiently by rubbing the acid and rinsing it. Consequently, it produces an optimal interface for bonding. Etching with 37\% phosphoric acid associated with rubbing also creates larger dentinal tubules, and improves enamel's porosity. All these points could increase the bonding strength in the hybrid layer.

\section{CONFLICT OF INTEREST}

The authors declare no potential conflicts of interest with respect to the research, authorship, and/or publication of this article.

\section{References}

1. Hu JC, Chun YH, Al Hazzazzi T, Simmer JP. Enamel formation and amelogenesis imperfecta. Cells Tissues Organs 2007; 186: 78-85.

2. Sabel N. Enamel of primary teeth morphological and chemical aspects. Swed Dent J Suppl 2012; 222 (Suppl 1): 1-77.

3. McGuire JD, Walker MP, Mousa A, Wang Y, Gorski JP. Type VII collagen is enriched in the enamel organic matrix associated with the dentin-enamel junction of mature human teeth. Bone 2014; 63: 29-35.

4. Brännström M, Glantz PO, Nordenvall KJ. The effect of some cleaning solutions on the morphology of dentin prepared in different ways: an in-vivo study. ASDC J Dent Child 1979; 46: 291-5.

5. Sattabanasuk V, Vachiramon V, Qian F, Armstrong SR. Resindentin bond strength as related to different surface preparation methods. J Dent 2007; 35: 467-475.

6. Gwinnett AJ. Smear layer: morphological considerations. Oper Dent Suppl 1984; 3: 2-12.

7. Ogata M, Harada N, Yamaguchi S, Nakajima M, Pereira PN, Tagami J. Effects of different burs on dentin bond strengths of selfetching primer bonding systems. Oper Dent 2001; 26: 375-382.

8. Barros JA, Myaki SI, Nör JE, Peters MC. Effect of bur type and conditioning on the surface and interface of dentine. J Oral Rehabil 2005; 32: 849-856.

9. Tay FR, Carvalho R, Sano H, Pashley DH. Effect of smear layers on the bonding of a self-etching primer to dentin. J Adhes Dent 2000; 2: 99-116.

10. Koibuchi H, Yasuda N, Nakabayashi N. Bonding to dentin with a self-etching primer: the effect of smear layers. Dent Mater 2001; 17: 122-126.

11. Eick JD, Gwinnett AJ, Pashley DH, Robinson SJ. Current concepts on adhesion to dentin. Crit Rev Oral Biol Med 1997; 8: 306-335.

12. Baier RE. Principles of adhesion. Oper Dent 1992; Suppl 5: 1-9.

13. Gu Xh, Mao Cy, Liang C, Wang HM, Kern M. Does endodontic post space irrigation affect smear layer removal and bonding effectiveness? Eur J Oral Sci 2009; 117: 597-603.

14. Bertolotti RL. Conditioning of the dentin substrate. Oper Dent Suppl 1992; 17 (Suppl 5): 131-136.

15. Eliades G, Palaghias G, Vougiouklakis G. Effect of acidic conditioners on dentin morphology, molecular composition and collagen conformation in situ. Dent Mater 1997; 13: 24-33.

16. Harashima T, Kinoshita J, Kimura Y, et al. Morphological comparative study on ablation of dental hard tissues at cavity preparation by Er:YAG and Er,Cr:YSGG lasers. Photomed Laser Surg 2005; 23: 52-55

17. Kharouf N, Mancino D, Naji-Amrani A, Eid A, Haikel Y, Hemmerle J. Effectiveness of etching by three acids on the morphological and chemical features of dentin tissue. J Contemp Dent Pract 2019; 20: 915-919. 
18. Kharouf N, Rapp G, Mancino D, Hemmerlé J, Haikel Y, Reitzer F. Effect of etching the coronal dentin with the rubbing technique on the microtensile bond strength of a universal adhesive system. Dent Med Probl 2019; 56: 343-348.

19. Tao L, Pashely DH, Boyd L. Effect of different types of smear layers on dentin and enamel shear bond strengths. Dent Mater 1988; 4 : 208-216.

20. Hashimoto M, Ohno H, Sano H, Kaga M, Oguchi H. In vitro degradation of resin-dentin bonds analyzed by microtensile bond test, scanning and transmission electron microscopy. Biomaterials 2003; 24: 3795-3803.

21. Perdigao J, Swift EJ. Analysis of dental adhesive systems using scanning electron microscopy. Int Dent J 1994; 44: 349-359.

22. Oyarzún A, Rathkamp H, Dreyer E. Immunohistochemical and ultrastructural evaluation of the effects of phosphoric acid etching on dentin proteoglycans. Eur J Oral Sci 2000; 108: 546-554.

23. Besinis A, van Noort R, Martin N. Infiltration of demineralized dentin with silica and hydroxyapatite nanoparticles. Dent Mater 2012; 28: 1012-1023.

24. Young RA. Implications of atomic substitutions and other structural details in apatites. J Dent Res 1974; 53: 193-203.

25. Warshawsky H. Organization of crystals in enamel. Anat Rec 1989; 224: 242-262.

26. Weber DF. Sheath configurations in human cuspal enamel. J Morphol 1973; 141: 479-489.

27. Simmelink JW, Nygaard VK, Scott DB. Theory for the sequence of human and rat enamel dissolution by acid and by EDTA: a correlated scanning and transmission electron microscope study. Arch Oral Biol 1974; 19: 183-197.

28. Månson-Rahemtulla B, Retief DH, Jamison HC. Effect of concentrations of phosphoric acid on enamel dissolution. J Prosthet Dent 1984; 51: 495-498.

29. Van Meerbeek B, Inokoshi S, Braem M, Lambrechts P, Vanherle G. Morphological aspects of the resin-dentin interdiffusion zone with different dentin adhesive systems. J Dent Res 1992; 71: 15301540 .

30. Chow LC, Brown WE. Phosphoric acid conditioning of teeth for pit and fissure sealants. J Dent Res 1973; 52: 1158.

31. Huang $\mathrm{Ch}$, Cao P. Tuning Ca:P ratio by $\mathrm{NaOH}$ from monocalcium phosphate monohydrate (MCPM). Materials Chemistry and Physics 2016; 181: 159-166.

32. Turner C, Courts FJ, Gombola GG. The removal of phosphoric acid and calcium phosphate precipitates: an analysis of rinse time. Pediatr Dent 1987; 9: 208-211. 